\title{
Flora cactológica y especies asociadas en el área natural protegida Sierra Corral de los Bandidos, Nuevo León, México
}

\section{Cactus list and asociated plants of the protected natural area Sierra Corral de Los Bandidos, Nuevo León, Mexico}

María del Pilar Carmona-Lara ${ }^{1 *}$, Rahim Foroughbakhch ${ }^{1}$, Alfredo Flores-Valdés ${ }^{2}$, Marco A. Alvarado ${ }^{1}$ y Marco A. Guzmán-Lucio ${ }^{1}$

${ }^{1}$ Facultad de Biología, Depto. de Botánica, Universidad Autónoma de Nuevo León, Apartado postal F-2 Cd. Universitaria, 66451, San Nicolás de los Garza, Nuevo León, México.

${ }^{2}$ Centro de Investigación y de Estudios Avanzados-IPN-Saltillo Coahuila, Carretera Saltillo Monterrey Km. 13.5, Ramos Arizpe Coahuila, México.

*Correspondencia: mapilicl@prodigy.net.mx

\begin{abstract}
Resumen. El área natural protegida (ANP) Sierra Corral de los Bandidos ubicada en la sierra Madre Oriental, al noroeste de Monterrey, sufre el impacto de actividades antropológicas asociadas al matorral submontano (ganadería, agricultura, colecta y urbanismo), disminuyendo sus recursos naturales y amenazando sus especies endémicas, principalmente cactáceas. El propósito del estudio fue conocer la diversidad de cactáceas y especies asociadas en zonas de amortiguamiento y núcleo. Para ello se determinaron índices de riqueza y similitud utilizando un muestreo estratificado con cuadrantes a lo largo de transectos orientados por gradientes altitudinales según su zonificación. En total se registraron 112 taxa (30 cactáceas), 87 ( 24 cactáceas) en zona de amortiguamiento y 80 (19 cactáceas) en zona núcleo. Por su densidad, frecuencia y abundancia sobresalieron Echinocereus stramineus (Engelm.) Engelm. ex F. Seitz, Cylindropuntia leptocaulis F. M. Knuth in Backeb et F. M. Knuth, Mammillaria melanocentra Poselg., Neolloydia conoidea (DC) Britton et Rose, (Cactaceae); Erioneuron avenaceum (H. B et K.) Tateoka, (Poaceae); Viguiera stenoloba S. F. Blake; Zexmenia hispida (Kunth) A. Gray, (Asteraceae) y Agave lechuguilla Torr, (Agavaceae). Existe diferencia significativa entre las poblaciones de cactus de las zonas del ANP, según Jacquard (13\%), Sörensen (38\%) y Morisita (0.44). Ocho cactáceas (7 endémicas) están registradas en algún estatus de la NOM-ECOL-059, 2001.
\end{abstract}

Palabras clave: cactáceas, matorral desértico, distribución, Nuevo León, México.

\begin{abstract}
The Sierra Corral de los Bandidos is a natural protected area located in the Sierra Madre Oriental mountain range northwest of Monterrey city. This preserve suffers the impact of human activities in the form of cattle ranching, agriculture, harvest of wild plants, and urbanism), diminishing its natural resources and threatening its endemic species, especially from the cactaceae family. The purpose of this study was to obtain information on the diversity of cacti and associated species in the buffer and nucleus zones of the preserve. Stratified sampling with quadrats along transects oriented along elevational gradients were carried out to estimate richness and similarity indices. A total of 112 taxa (30 Cactaceae) were found: 87 ( 24 cactaceae) in the buffer zone and 80 (19 cactaceae) in the nucleus zone. The most conspicuous cactus species due to their density, frequency, and abundance were Echinocereus stramineus (Engelm.) Engelm. ex F. Seitz, Cylindropuntia leptocaulis F. M. Knuth in Backeb et F. M. Knuth, Mammillaria melanocentra Poselg., Neolloydia conoidea (DC) Britton et Rose, (Cactaceae); Erioneuron avenaceum (H. B et K.) Tateoka, (Poaceae); Viguiera stenoloba S. F. Blake; Zexmenia hispida (Kunth) A. Gray, (Asteraceae) and Agave lechuguilla Torr, (Agavaceae). Significative differences were found between the Cactaceae plants for the zones of the protected area, as shown by the indices obtained: Jacquard (13\%), Sörensen (38\%) and Morisita (0.44). Eight cactus species (7 endemic) from this report are listed as receiving some level of protection under Mexican conservation law.
\end{abstract}

Key words: Cactaceae, desert scrubland, distribution, protected areas, Nuevo León, Mexico.

\section{Introducción}

México es 1 de los 5 países con mayor diversidad biológica del mundo. Entre el 10 y el $12 \%$ de las especies

Recibido: 29 enero 2007; aceptado: 22 enero 2008 del planeta se encuentran en este territorio; suman más de 200 mil especies, que ocupan el cuarto lugar en el mundo en cuanto a riqueza de plantas y el primero en diversidad de cactáceas (Hunt, 1992; Casas, 2005), que alcanzan alrededor de 1500 especies dentro de 100 géneros integrados en 3 subfamilias (Hershkovitz y Zimmer, 1977). 
Aproximadamente la tercera parte de estas cactáceas, 563 especies en 48 géneros con el $78 \%$ de especies endémicas (Alanís et al., 2004), se encuentra especialmente en la región que comprende los estados de Coahuila, San Luis Potosí, Tamaulipas y Nuevo León, localizados en la porción sureste del desierto chihuahuense (Hernández y Godínez, 1994; Hernández y Bárcenas, 1995, 1996; Alanís et al., 1996). Gran parte de esta diversidad se resguarda dentro de las áreas naturales protegidas (Falk, 1990).

En el año 2000, el gobierno del estado de Nuevo León decretó el sistema de áreas naturales protegidas (ANP), entre las que destaca Sierra Corral de los Bandidos localizada en los límites de Nuevo León y Coahuila (Fig. 1). Esta ANP se estableció con fines de preservación de especies endémicas, principalmente por el creciente desarrollo industrial y urbano propio de la región; además, pertence al conjunto de áreas naturales protegidas de competencia estatal que rodea la zona metropolitana y que se ubica frente al Parque Nacional Cumbres de Monterrey (Gobierno del Estado de Nuevo León, 2000). El área no tiene asentamientos humanos, cuenta con una vía de acceso que se dirige a unas torres de comunicación satelital. El régimen de propiedad es privado y el usufructo principal es para el tránsito a las torres de microondas que pertenecen a industrias particulares y paraestatales además de ser empleada por vecinos para pastoreo de ganado equino y caprino, y recolección de especies no maderables, como cactus, agaves y candelilla (Sauceda, 1985).

No obstante, por ser área natural protegida, el uso de suelo obligado es la educación ambiental, la investigación y/o el establecimiento de unidades de manejo para reproducción de especies nativas, actividades que por no ser comunes, resultan de poco interés para los propietarios. Por tanto, es prioritario el estudio de la riqueza biológica para poder establecer las bases que permitan un adecuado manejo que resulte en alternativas útiles para propietarios y usuarios. Especialmente las cactáceas ofrecen una gran gama de posibilidades para su aprovechamiento, entre las que se cuenta la producción de tinturas para la industria alimenticia, extracción de alcaloides de uso médico, obtención de alimento para consumo humano, alimento fresco y/o forraje para la ganadería y plantas de ornato, así también por el importante papel que como parte esencial de la flora desempeñan dentro del ecosistema.

El conocimiento botánico de la Sierra Corral de los Bandidos consiste sólo de registros de flora y fauna presentes en el programa de manejo realizado por la entidad administrativa del Gobierno del estado de Nuevo León (Gobierno del Estado de Nuevo León, 2000), sin embargo, no existe información sobre estudios botánicos de la misma. Por lo anterior, y a fin de establecer las bases para un programa de manejo de ANP, se procedió al estudio de la diversidad de cactáceas y sus especies asociadas con fines de protección y aprovechamiento adecuado del recurso.

\section{Material y métodos}

Área de estudio. El ANP Sierra Corral de los Bandidos se encuentra dentro del Municipio de García, abarca 1175.01 ha, con altitudes de 1000 a $1640 \mathrm{~m}$ snm, con clima de tipo
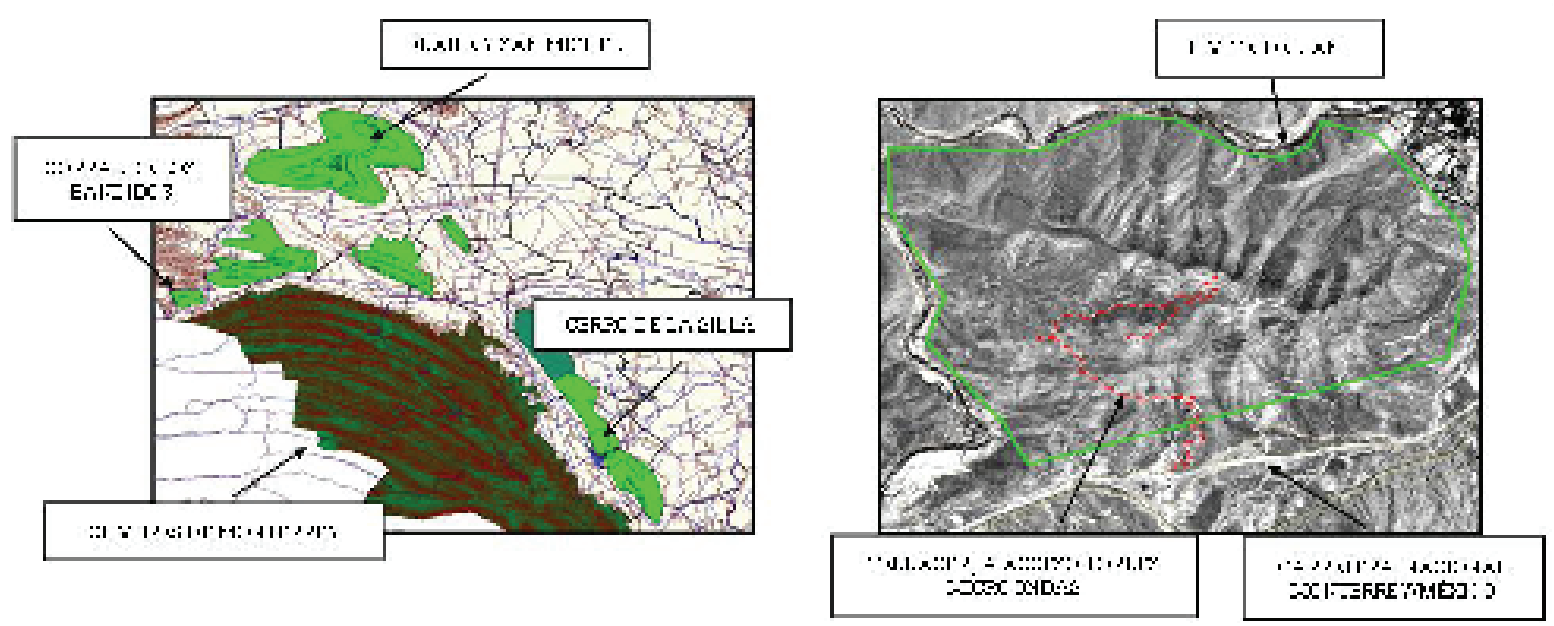

Figura 1. Ubicación del área natural protegida Sierra Corral de los Bandidos, Nuevo León, en relación con otras áreas naturales protegidas de la zona urbana y fotografía satelital de las elevaciones topográficas y sus caminos. Tomado del Programa de manejo (Gobierno del Estado de Nuevo León, 2002). 
seco BS0 y muy seco BW (García, 1973). La precipitación anual va de 200 a $400 \mathrm{~mm}$. Se encuentra en la flexión de la sierra Madre Oriental conocida como anticlinorio de Arteaga, al este de Saltillo y sur de Monterrey dentro de la subprovincia llamada pliegues de Saltillo-Parras. Los tipos de vegetación corresponden a matorral desértico rosetófilo con fisonomía de crasi-rosulifolio espinoso y nopalera. Esta localizada dentro de la región hidrológica RH24 río Bravo-Sosa y en la cuenca río Bravo-San Juan, subcuenca río Pesquería que bordea la parte norte y oeste cercana al área natural (INEGI, 1986).

Se divide en zona de amortiguamiento y zona núcleo; la primera es un área de recuperación (Fig. 2), presenta clima seco con lluvia escasa todo el año (BWhx'), su suelo es tipo litosol, con temperaturas de 18 a $20{ }^{\circ} \mathrm{C}$ y precipitación anual de 300 a $400 \mathrm{~mm}$; la segunda (área de uso restringido), presenta clima muy seco con lluvia escasa todo el año (BSOhx'), con suelo tipo regosol, temperaturas de 20 a $22{ }^{\circ} \mathrm{C}$ y precipitación anual de 200 a $300 \mathrm{~mm}$. (Gobierno del Estado de Nuevo León, 2002), con vegetación de matorral desértico rosetófilo, crasirosulifolio espinoso, subinerme, pastizal natural y nopalera (Fig. 2). Caracterizándose por presentar especies carnosas en forma de roseta, como lechuguilla (Agave lechuguilla), guapilla (A. striata Zucc), sotol, (Dasylirion texanum Scheele), con cactáceas globulares y de raqueta, y plantas espinosas o pequeños arbustos, como guajillo (Acacia berlandieri Benth), mezquite (Prosopis gladulosa Torr), chaparro prieto (Acacia rigidula Benth) y gobernadora (Larrea tridentata Coult); gramíneas, como navajita (Bouteloua trifida Thurb. ex S.Wats), falso borreguero
(Erioneuron pulchellum H.B y K.); zacate de 3 barbas o garañona (Aristida sp. L.) y zacate pelusa (Tridens sp. Roem. y Schul.), entre otras.

Por su orientación, la zona de amortiguamiento cuenta con mayor cantidad de horas luz, los rayos del sol penetran más fácilmente por la altura de su vegetación (máxima de $0.65 \mathrm{~m}$ ), en comparación con la zona núcleo (altura máxima de $1.20 \mathrm{~m}$ ). Los suelos en la zona núcleo son ligeramente más profundos y la escorrentía e hidrografía subterránea le favorecen aún y cuando el tipo de clima es más extremo que el de la zona de amortiguamiento.

La ANP no cuenta con poblados, contiene unas torres de comunicación y carretera de acceso a éstas. Los vecinos son los usuarios del área; las principales actividades son la ganadería caprina y equina extensiva, la extracción de agaves y cactus para alimento fresco para el ganado en época de sequía (marzo-mayo) y para uso medicinal y de consumo humano, en menor grado se extrae candelilla y lechuguilla para su comercialización (Sauceda, 1985).

Mediante sistemas de información geográfica (imágenes de satélite) se ubicaron y marcaron 4 sitios de colecta, tomando como base la información existente en los programas de manejo del ANP, proporcionada por la autoridad administrativa de la misma, y se consideraron diferentes criterios, como tipo de suelo, exposición al sol, climas, topografía, vegetación y la zonificación decretada para esta ANP (Fig. 2). El trabajo en campo se desarrolló de noviembre de 2004 a diciembre de 2005.

Se realizaron 2 muestreos el primero para el análisis cuantitativo de la estructura de las comunidades vegetales, para el cual se utilizaron transectos lineares de 130 a
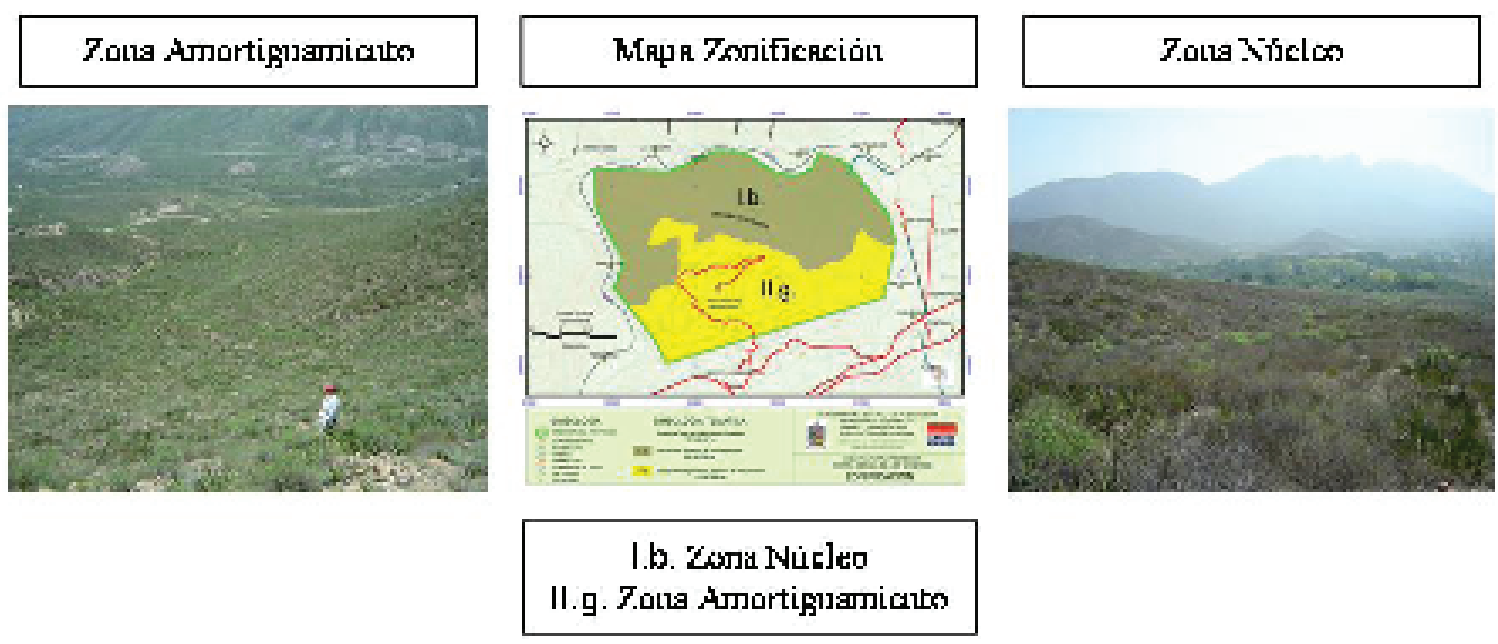

I.g. 7.ous Amortipuaniaus

Figura 2. Área natural protegida Sierra Corral de los Bandidos. Fotografías del paisaje de la zona de amortiguamiento en dirección al sur, en gradiente descendiente y de la zona núcleo en dirección al norte, en gradiente descendiente. Fotografías inéditas de Héctor Ramos (2005). Mapa de la zonificación establecida en el programa de manejo (Gobierno del Estado de Nuevo León, 2002). 
$150 \mathrm{~m}$ de longitud ubicados en forma paralela al gradiente altitudinal, 2 para cada zona. A lo largo de éstos, se colocaron cuadrantes de $1 \mathrm{~m}^{2}$ (Braun-Blanquet, 1945) cada $10 \mathrm{~m}$; el lado de colocación del cuadrante fue determinado en forma aleatoria. En estos cuadrantes se registraron las especies vegetales presentes y para cada una de ellas se determinó número de individuos, altura y cobertura. Además se registró el porcentaje de humedad y temperatura, así como el lado de exposición al sol, la altitud y latitud. Con estos datos se realizó el análisis florístico por zonas, determinando la distribución, frecuencia, abundancia, y valor de importancia de cada una de las especies vegetales de acuerdo con los métodos propuestos por Matteucci y Colma (1982) y Mueller-Dombois y Ellenberg (1974). Adicionalmente, para los cálculos de similitud, diversidad y riqueza de cactáceas y plantas asociadas en las zonas del ANP, se realizó el segundo muestreo, donde se colocaron 4 parcelas rectangulares de $20 \mathrm{~m}$ de ancho, cuyo centro era atravesado por los transectos lineares $(20 \mathrm{~m})$; el primero de 20 x 130 m, el segundo de 20 x 140 m y 2 de 20 x 150 $\mathrm{m}$, con un total de $1140 \mathrm{~m}^{2}$. En cada parcela, se registró el número de individuos de las especies de cactáceas y de las plantas asociadas a éstas en un área de 1 a $2 \mathrm{~m}^{2}$, dependiendo de la dimensión de las cactáceas; para aquellas de un diámetro aproximado de $1 \mathrm{a} 6 \mathrm{~cm}$ y para las mayores de $10 \mathrm{~cm}$, respectivamente. La identificación de las especies se llevó a cabo en el Laboratorio de Fanerógamas del Departamento de Botánica de la Universidad de Nuevo León (UNL), comparando el material con las muestras del herbario de la institución y elaborando un catálogo de las plantas colectadas con el tradicional método de prensado y secado.

El registro de cactáceas se realizó in situ, mediante fotografías y por colecta de rescate de ejemplares, mismos que se depositaron en el herbario de la Facultad de Ciencias Biológicas de la Universidad de Nuevo León.

Asimismo, y a fin de comparar las comunidades vegetales, se determinaron la diversidad alfa, mediante los parámetros de riqueza (índice de Margalef), diversidad (índice de Shannon-Weiner) y equitatividad (índice de Shanon). Así como la diversidad beta (similitud entre comunidades), mediante los índices cualitativos de Jaccard y Sorensen y el índice cuantitativo de Morisita (Gurevitch et al., 2002). Lo anterior con el fin de observar diferencia entre las zonas del ANP y sentar las bases para su particular manejo.

\section{Resultados}

La composición florística de la Sierra Corral de los Bandidos corresponde a 112 taxa agrupados en 37 familias, de los cuales 87 especies (27 familias) corresponden a la zona de amortiguamiento y 80 especies (31 familias) a la zona núcleo (Apéndice 1 y Cuadro 1). Los estratos vegetales presentes en el ANP corresponden a alturas promedio para la zona núcleo y de amortiguamiento de $21 \mathrm{~cm}$; alcanzan valores máximos de $120.5 \mathrm{~cm}$ y $65 \mathrm{~cm}$, respectivamente. Las altitudes en la zona oscilaron de 1305 m snm a $1407 \mathrm{~m}$ snm, para la zona de amortiguamiento y de $1041 \mathrm{~m}$ snm a $1155 \mathrm{~m}$ snm, para la zona núcleo. En el ANP predominan las familias Cactaceae con 30 especies, seguida de Poaceae con 14, Asteraceae con 11, Euphorbiaceae con 7, Mimosaceae con 6 y Agavaceae, Boraginaceae, Malvaceae y Zygophyllaceae con 3 especies cada una.

Sin considerar las cactáceas, la zona de amortiguamiento cuenta con 26 familias y 63 especies, y la zona núcleo con 30 familias y 61 especies. Existen especies exclusivas, 21 en la zona de amortiguamiento y 19 en la zona núcleo, así como 42 especies compartidas (Apéndice 1). La densidad de individuos es mayor en la zona núcleo que en la de amortiguamiento. De acuerdo con el número de individuos, la familia Agavaceae presenta una densidad del $27.3 \%$ (3 especies) en la zona de amortiguamiento y el $40.9 \%$ ( 2 especies) en la zona núcleo; Poaceae, el 28.5\% (11 especies) en la zona de amortiguamiento y el 16.8 $\%$ (9 especies) en la zona núcleo; Asteraceae, el 22.2\% (10 especies) en la zona de amortiguamiento y el $16.3 \%$ (9 especies) en la zona núcleo; Mimosaceae, el 4.4\% (6 especies) en la zona de amortiguamiento y el $3.7 \%$ en la zona núcleo (6 especies) y la familia Euphorbiaceae, el $2.4 \%$ (6 especies) y el $3 \%$ (5 especies) respectivamente para las zonas de amortiguamiento y núcleo.

La especie más abundante en ambas zonas es A. lechuguilla (35\%) (Apéndice 1). En la zona de amortiguamiento, las especies más frecuentes fueron $A$. lechuguilla, (13\%), seguida de Viguiera stenoloba (8\%), Tridens muticus Nash (7\%), Echinocereus stramineus y B. trifida (6\%). Las especies con mayor densidad fueron $E$. stramineus (44\%) A. lechuguilla (12\%) y T. muticus (7\%). Asimismo, las especies A. lechuguilla (35\%), V. stenoloba (11\%), B. trifida y T. muticus (5\%), presentaron mayor cobertura vegetal. Sin embargo, las especies con mayor valor de importancia florística, al considerar abundancia, densidad y frecuencia fueron: A. lechuguilla (20\%), E. stramineus (18\% ) y V. stenoloba (8\%) (Apéndice 2 y Fig. 3).

En la zona núcleo, las especies más frecuentes fueron A. lechuguilla, Carlowrightia pubens A. Gray, V. stenoloba y Aristida wrightii Nash. Mientras que las especies con mayor densidad fueron A. lechuguilla, E. stramineus y C. pubens. Mientras que las de mayor cobertura vegetal fueron A. lechuguilla, V. stenoloba y A. wrightii. En esta 
Cuadro 1. Cactáceas registradas en el área natural protegida Sierra Corral de los Bandidos, Nuevo León, por ambos métodos (cuadrantes y transectos adicionales), señalando número de individuos en Zn: Zona núcleo y Za: Zona de amortiguamiento y su estatus normativo

\begin{tabular}{llll}
\hline Especies।Individuos presentes en $1140 \mathrm{~m}^{2}$ & $Z A$ & ZN & Est. \\
\hline
\end{tabular}

Astrophytum capricorne (A. Dietr.) Britton et Rose 1992

Coryphantha delicata L. Bremen 1979

Coryphantha saliniensis (Poselg.) A.D.Zimmerman ex Dicht et A. Lüthy 1998

Coryphantha sulcata (Engelm.) Britton et Rose 1923

Cylindropuntia imbricata (Haw.) F.M. Knuth in Backeb. et F.M. Knuth 1935

Cylindropuntia leptocaulis (DC.) F.M. Knuth in Backeb. et F.M. Knuth 1935

Echinocactus horizonthalonius Lem. 1839

Echinocereus enneacanthus Engelm. in Wisl. 1848

Echinocereus enneacanthus variedad brevispinus (W.O. Moore) L.D. Benson 1969

Echinocereus longisetus subespecie delaetii (GürKe) N.P. Taylor 1997

Echinocereus pentalophus (DC.) Lem 1868

Echinocereus poselgeri Lem. 1868

Echinocereus stramineus (Engelm.) Engelm. ex F. Seitz 1870

Ferocactus hamatacanthus (Muehlenpf.) Britton et Rose 1992

Grusonia moellerii (A. Berger) E.F. Anderson 1999

Lophophora williamsii (Lem. ex Salm-Dyck) J. M. Coult. 1894

Mammillaria heyderi Muehlenpf. 1848

Mammillaria melanocentra Poselg. 1855

Mammillaria plumosa F.A.C. Weber in Bois 1898

Mammillaria pottsii Scheer ex Salm-Dyck 1850

Mamillaria roseoalba Boed. 1929

Mamilloydia candida (Scheidw.) Buxb. 1951

Neolloydia conoidea (DC.) Britton et Rose 1922

Opuntia engelmannii Salm-Dyck 1850

Opuntia engelmannii spp. lindheimeri (Engelm.) U. Guzmán et Mandujano 2003

Opuntia microdasys (Lehm.) Pfeiff. 1837

Opuntia rastrera F.A.C. Weber in Bois 1898

Stenocactus multicostatus (Hildm. ex K. Schum.) A.W. Hill 1933

Thelocactus bicolor (Galeotti ex Pfeiff.) Britton et Rose 1922

Thelocactus rinconensis (Poselg.) Britton et Rose 1923

Totales
A, E

Pr, E

$\begin{array}{lll}1 & 0 & \text { Pr, } \\ 0 & 24 & --\end{array}$

$9 \quad 646 \quad--$

$2 \quad 2 \quad--$

$17 \quad 231 \quad--$

$2 \quad 0 \quad--$

$1 \quad 0 \quad--$

$\begin{array}{lll}1 & 0 & \text { A, E } \\ 0 & 17 & -- \\ 1 & 0 & \\ 0 & 1 & \text { Pr }\end{array}$

$2869 \quad 1562$

$2623 \quad$ Pr, E

$27 \quad 0 \quad--$

$11 \quad 126$--

$04 \quad--$

$16 \quad 24$--

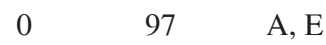

$\begin{array}{lll}179 & 3 & --\end{array}$

$25 \quad 37 \quad \operatorname{Pr}, \mathrm{E}$

02 A, E

$278 \quad 0 \quad-$

$2 \quad 10$--

$3 \quad 15$

$13 \quad 0 \quad-$

10

50

$\begin{array}{lll}42 & 1 & --\end{array}$

$\begin{array}{lll}3623 & 2844 & 8\end{array}$

ZA: zona de amortiguamiento; $Z N$ : zona núcleo; EST.: estatus; E: endémico de México; A: amenzada y Pr: sujeta a protección especial. Nomenclatura: Guzmán, 2003. 


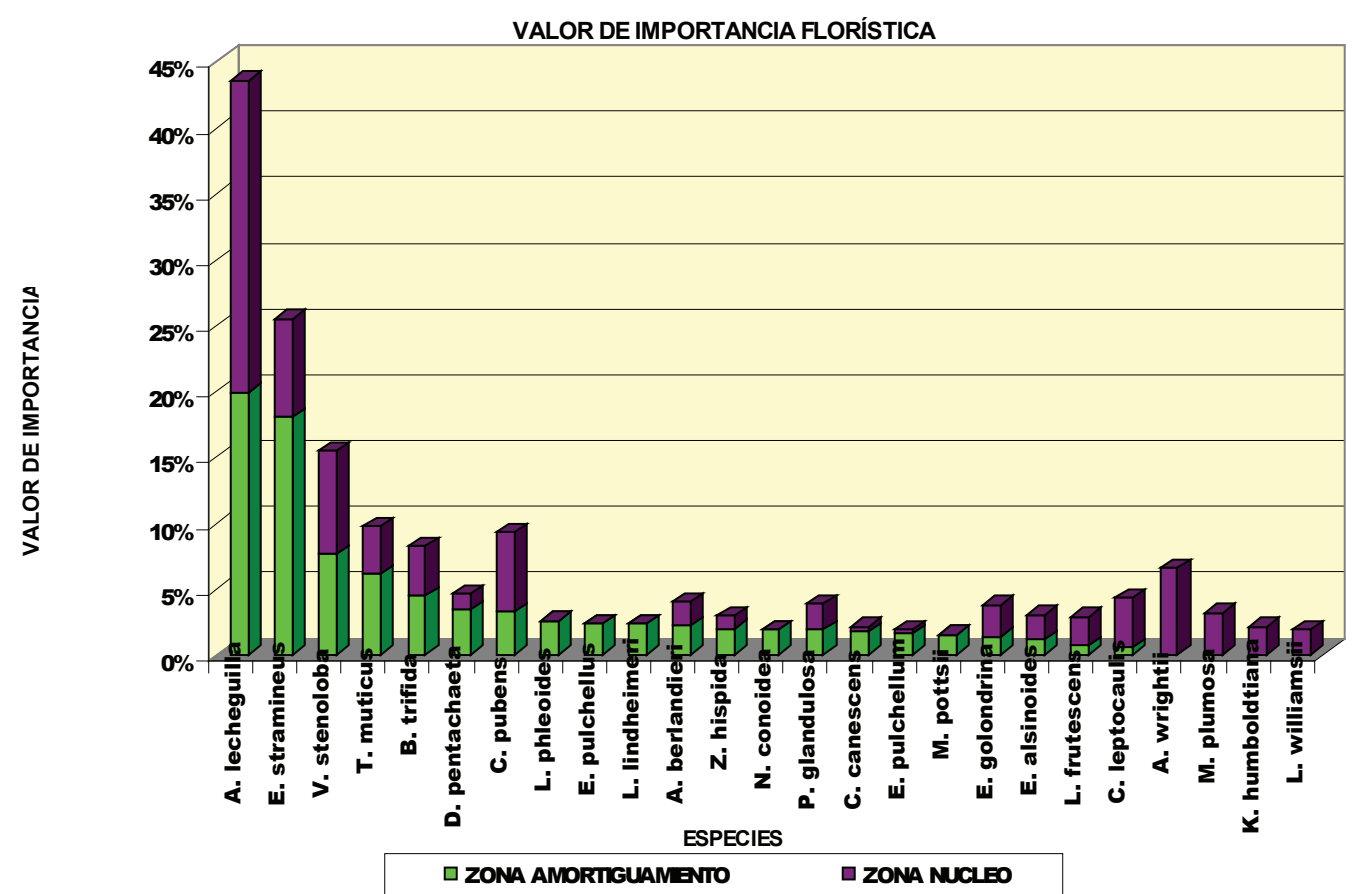

Figura 3. Valor de importancia (promedio de densidad, abundancia y frecuencias relativas) de las plantas de mayor distribución en la zona de amortiguamiento y zona núcleo del área natural protegida Sierra Corral de los Bandidos, Nuevo León.

zona A. lechuguilla, seguida de $V$. stenoloba, $A$. wrightii y E. stramineus representan las especies con mayor valor de importancia florística (Apéndice 3 y Fig. 3).

$\mathrm{El}$ análisis de las comunidades vegetales presentes en la zona núcleo y de amortiguamiento del ANP mediante el empleo de índices de riqueza (diversidad alfa) indican diferencia entre las zonas del ANP, registrando la zona núcleo como la de mayor riqueza de especies (Dmg= 7.37), de diversidad $\left(\mathrm{H}^{\prime}=2.82\right)$ y equitatividad $(\mathrm{E}=0.73)$, por consiguiente, menor dominancia $(\mathrm{L}=0.10)$ para esta zona, según los índices de riqueza de Margalef (Dmg), de diversidad de Shannon-Weinner $(\mathrm{H})$, de equitatividad (E) y de dominancia de Simpson (L) (Cuadro 2).

Asimismo, el análisis florístico comparativo (diversidad beta) para las zonas de amortiguamiento y núcleo sugiere diferencias entre ambas, toda vez que la similitud, de acuerdo con el índice cualitativo de Jaccard, corresponde al 25\%; con el índice cuantitativo de Sörensen-Dice al $40 \%$, en tanto que el índice cuantitativo de Morisita indica una similitud de $\mathrm{M}=0.78$.

Diversidad de cactáceas. El 27\% de las especies del ANP pertenecen a la familia Cactaceae, encontrándose para la zona de amortiguamiento 24 especies y 19 para la zona núcleo, para un total de 30 especies (14 géneros). De este total, 13 especies (8 géneros) están presentes en ambas zonas, 11 (8 géneros) están presentes sólo en la zona de amortiguamiento y 6 (4 géneros) son exclusivas de la zona núcleo, sobresalen por su densidad: Astrophytum capricorne (A. Dietr.) Britton et Rose, Mammillaria plumosa F. A. C. Weber in Bois y Neolloydia conoidea (Cuadro 1). El $64 \%$ de los cactus muestreados corresponden a esta última.

Los 30 taxa registrados pertenecen a 14 géneros entre los que sobresalen Echinocereus con 6 especies, Mammillaria con 5, Opuntia con 4, Coryphantha con 3 y Cylindropuntia junto con Thelocactus con 2. Ocho de las especies presentes, se encuentran dentro de algún estatus de la Norma Oficial Mexicana (NOM-059-ECOL-2001) y 7 de ellas se registran como endémicas (Cuadro 1).

Las cactáceas más abundantes en la zona de amortiguamiento fueron E. stramineus (79\%), N. conoidea (7\%) y $M$. pottsii (5\%). Mientras que para la zona núcleo fueron E. stramineus (55\%), Coryphantha sulcata (Engelm.) Britton et Rose (23\%), C. leptocaulis (8\%), Lophophora williamsii (Lem. ex Salm-Dyck) J. M. Coult (4\%) y M. plumosa (3\%) (Cuadro 1 y Figs. 4 y 5).

En la comunidad de cactáceas de la zona de amortiguamiento las especies con mayor valor de importancia fueron: E. stramineus, M. melanocentra y $N$. conoidea (Apéndice 2), mientras que para la comunidad de 
Cuadro 2. Algunos parámetros de diversidad en las zona de amortiguamiento y zona núcleo del área natural protegida Sierra Corral de los Bandidos, Nuevo León (considerando muestreos por cuadrantes y transectos adicionales sólo para cactáceas, y el muestreo por cuadrantes para todas las especies)

\begin{tabular}{lllll}
\hline Taxa & \multicolumn{2}{c}{$\begin{array}{c}\text { Todas las } \\
\text { especies }\end{array}$} & \multicolumn{2}{c}{$\begin{array}{c}\text { Sólo } \\
\text { cactáceas }\end{array}$} \\
\hline Zonas & $Z a$ & $Z n$ & $Z a$ & $Z n$ \\
$\mathrm{~N}$ & 836 & 587 & 3623 & 2844 \\
$\mathrm{Q}$ & $30 \mathrm{~m}^{2}$ & $27 \mathrm{~m}^{2}$ & $1140 \mathrm{~m}^{2}$ & $1140 \mathrm{~m}^{2}$ \\
$\mathrm{~S}$ & 45 & 48 & 24 & 19 \\
$\mathrm{Dmg}$ & 6.54 & 7.37 & 2.80 & 2.26 \\
$\mathrm{H}^{\prime}$ & 2.36 & 2.82 & 0.93 & 1.44 \\
$\mathrm{E}$ & 0.62 & 0.73 & 0.29 & 0.49 \\
$\mathrm{~L}$ & 0.22 & 0.10 & 0.64 & 0.36 \\
\hline
\end{tabular}

$Z a$ : zona de amortiguamiento; $Z n$ : zona núcleo; $\mathrm{N}=$ número de individuos muestreados; $\mathrm{Q}=$ superficie muestreada, $\mathrm{S}=$ número de especies, $\mathrm{Dmg}=$ índice de riqueza de Margalef; $\mathrm{H}^{\prime}=$ índice de diversidad de Shannon-Weinner; E= equitatividad; L=índice de dominancia de Simpson.

la zona núcleo fueron $C$. leptocaulis, E. stramineus y $M$. plumosa (Apéndice 3, Fig. 3).

El análisis de la diversidad en las poblaciones de cactáceas en ambas zonas indica que existen diferencias ya que la zona núcleo presentó mayor diversidad según el índice de Shannon-Weinner $\left(\mathrm{H}^{\prime}=1.44\right)$, lo cual se explica por su mayor equitatividad $(\mathrm{E}=0.49)$ y por su consiguiente menor dominancia $(\mathrm{L}=0.36)$ que la registrada para la zona de amortiguamiento. No obstante, esta última refiere mayor riqueza según Margalef $(\mathrm{Dmg}=2.80)$ y dominancia ( $\mathrm{L}=0.64)$ (Cuadro2).

La diferencia en cuanto a composición de especies entre las comunidades de cactáceas de las zonas del ANP es notable, toda vez que la similitud entre estas correspondió al $23 \%$ y $38 \%$ de acuerdo con los índices cualitativos de Jaccard y Sörensen-Dice respectivamente, y afirmándose cuantitativamente con el índice Morisita $(M=0.44)$.

En cuanto a la asociaciones observadas entre cactáceas y otras plantas, se encontró para la zona de amortiguamiento que las asociaciones más comunes fueron las de A. lechuguilla con E. stramineus y C. leptocaulis; $V$. stenoloba con E. stramineus; Erioneuron avenaceum con $E$. stramineus; Z. hispida con E. stramineus; además, algunas asociaciones entre cactáceas como en el caso de $M$. pottsii con E. stramineus. En la zona núcleo se identificaron las asociaciones de A. lechuguilla con C. leptocaulis, con $E$. stramineus y con C. sulcata; $V$. stenoloba con E. stramineus y con $C$. leptocaulis; esta última mostró también asociación frecuente con Tridens sp. y Z. hispida.

\section{Discusión}

La composición florística de la Sierra Corral de los Bandidos corresponde a un matorral de tipo desértico rosetófilo, con importante presencia de cactáceas (26.8\%), agaváceas (36\%), poáceas (21\%), y asteráceas(19\%), entre otras. El listado obtenido en el presente trabajo enriquece sustancialmente lo expuesto en el programa de manejo del ANP, donde se menciona una flora de 16 familias con 39 especies, dentro de la que participan con apenas 11 taxa las cactáceas, a diferencia de las 112 especies (30 cactáceas) registradas en el presente trabajo.

Es importante resaltar que no existen estudios previos específicos y comparativos sobre la vegetación de las zonas de esta ANP, lo cual dificulta su análisis; sin embargo, estudios botánicos, y cactológicos realizados en otras zonas del noreste de México coinciden al mencionar algunos géneros de amplia distribución, como es el caso de Cylindropuntia, Opuntia, Echinocereus, Echinocactus, Coryphantha, Mammillaria y Thelocactus que están presentes en el ANP, y que extienden su distribución desde Nuevo México hasta Zacatecas, en la región que corresponde al Desierto Chihuahuense (Waissman, 1982; Bravo, 1978; Bravo y Sanchez, 1991; Goettsch y Hernández, 2006). Asimismo, los resultados obtenidos muestran que algunas especies encontradas en el ANP, entre otras, Opuntia engelmannii sp. lindheimeri (Engelm.) U. Guzmán et Mandujano, Cylindropuntia imbricata (Haw.) F. M. Knuth in Backeb., C. leptocaulis, Opuntia microdasys (Lehm.) Pfeiff., O. engelmannii Salm-Dyck, $O$. rastrera F. A. C. Weber in Bois, Ferocactus hamatacanthus (Muehlenpf.) Britton et Rose, E. stramineus y C. sulcata están presentes en otros municipios del centro del estado, como Bustamante, García, Lampazos y Mina (Cavazos, 1977; Briones, 1984; García, 1985; Rocha, 2005).

La presencia y abundancia de las cactáceas en el área natural protegida Sierra Corral de los Bandidos se relaciona con la presencia de vegetación y fauna asociada, amen de las variables medioambientales propicias, entre otras, clima, temperatura, suelo, exposición al sol, topografía y altitud que crean microhábitats específicos para el desarrollo de especies restringidas, tales como $A$. capricorne, Echinocereus longisetus (Engelm.) Rümpler y M. plumosa (Hernández y Godínez, 1994; Hernández y Bárcenas 1996; González y Estrada, 2001).

Rocha (2005) describe la sierra Madre Oriental (SMO) como la región fisiográfica del estado de Nuevo León con mayor número de especies de cactáceas, con 86 de ellas, el $36 \%$ de las cuales se encuentran en el ANP Sierra Corral de los Bandidos, la cual ocupa apenas una pequeña fracción de la SMO; de ahí se puede comprender la riqueza e importancia de esta ANP como sitio de conservación. 


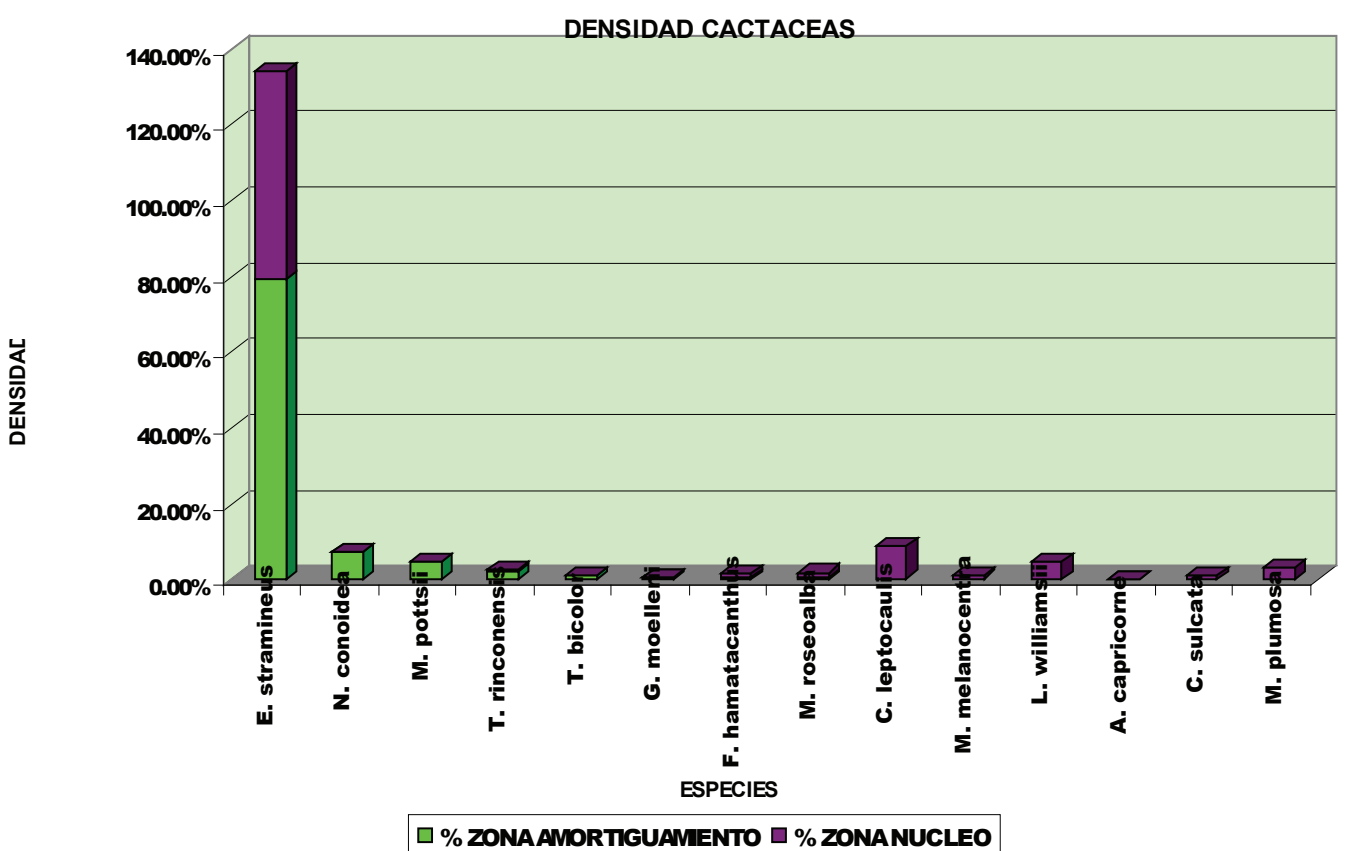

Figura 4. Densidad de las cactáceas más abundantes en la zona de amortiguamiento y zona núcleo del área natural protegida Sierra Corral de los Bandidos, Nuevo León.

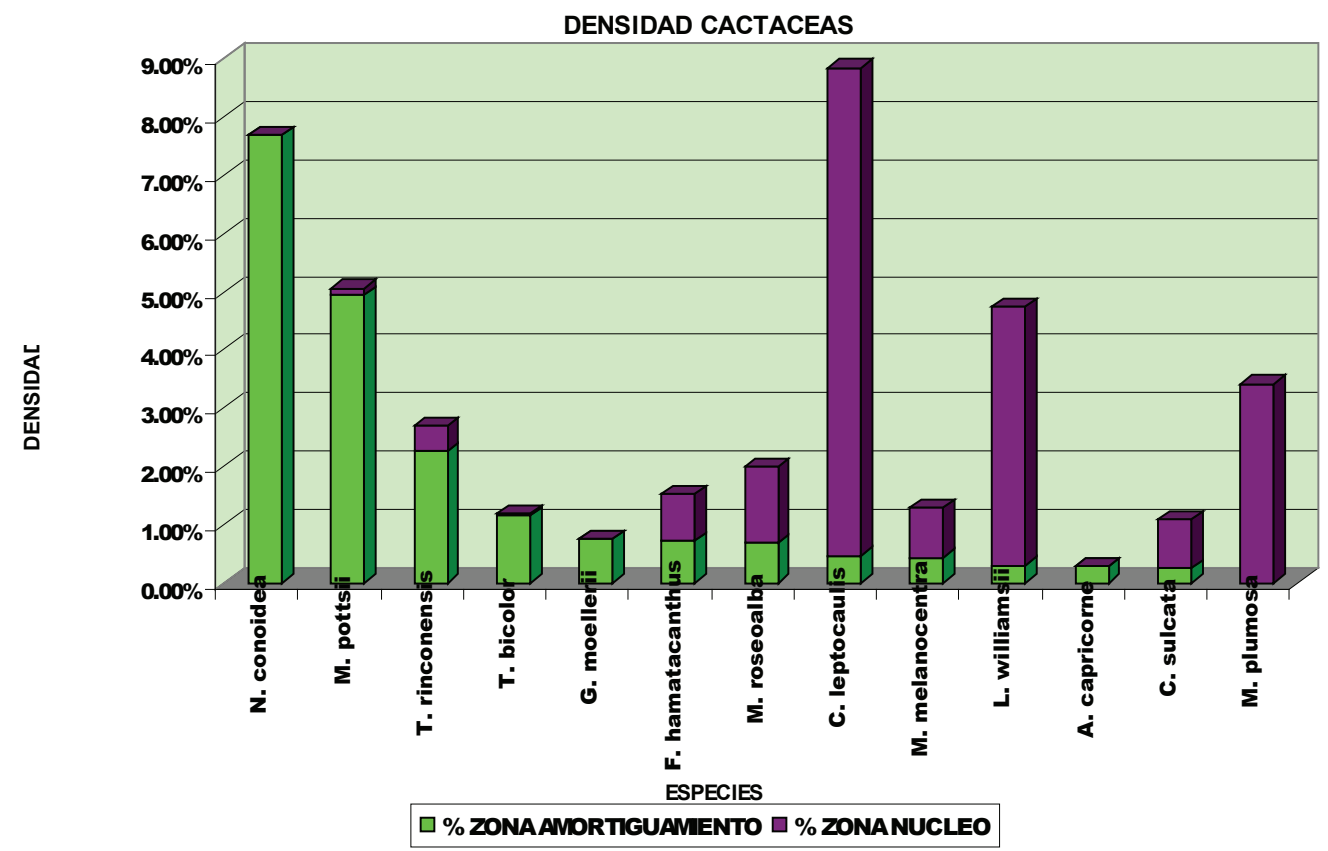

Figura 5. Densidad de las cactáceas más abundantes en la zona de amortiguamiento y zona núcleo del área natural protegida Sierra Corral de los Bandidos, Nuevo León, sin considerar la especie E. stramineus. 
Villarreal (2001) registra para Ramos Arizpe, que es la zona de Coahuila cercana al ANP, 65 taxa de cactáceas, entre los que sobresalen Opuntia (13 especies), Coryphantha (12), Echinocereus (10), Mammillaria (8) y Thelocactus (5).

En cuanto a la importancia de las especies en la comunidad, tenemos que la riqueza florística de Nuevo León asciende a 2380 especies de plantas vasculares distribuidas en $65000 \mathrm{~km}^{2}$, resultado de la presencia de 4 de las 5 zonas ecológicas terrestres del país, donde predominan la zona árida y la semiárida, registrando como consecuencia de su diversidad endemismos restringidos a un solo pico o peñasco que influyen en la de sus comunidades vegetales (Alanís y Ramírez, 2001; Alanís et al., 2004). Así, el estudio florístico de las zonas áridas representa importantes aportes para su manejo y la conservación de su riqueza (Cabrera y Gómez, 2005).

García (1985) registró valores de importancia mayores para las especies de $C$. leptocaulis y $O$. engelmannii sp. lindheimeri en el matorral desértico de Bustamante, Nuevo León, lo cual difiere con los resultados obtenidos para el ANP donde E. stramineus junto con $A$. lechuguilla fueron las de mayor importancia en la comunidad (Apéndices 1 y 2).

El análisis florístico de la zona de amortiguamiento registra índices de riqueza, diversidad y equitatividad menores y una consiguiente dominancia mayor que la zona núcleo, por lo que podemos considerar que esta comunidad vegetal se ha encontrado con mayores presiones y cambios en su ecosistema, lo que concuerda con la accesibilidad a la zona y el tráfico presente por la carretera de acceso a las torres de microondas. En tanto que la zona núcleo cuenta con mayor diversidad, riqueza y equitatividad, y una menor dominancia, reflejando menor disturbio.

Es importante señalar que dentro de la Norma Oficial Mexicana (NOM-ECOL-059, 2001) hay 5 especies de la zona núcleo: Echinocereus poselgeri Lem., F. hamatacanthus, M. plumosa, Mamillaria roseoalba Boed., Mamilloydia candida (Scheidw.) Buxb., y 5 de la zona de amortiguamiento que se emplea como zona de pastoreo de ganado caprino y equino, de recolección de candelilla y otros recursos no maderables, y que es el acceso a las torres de microondas; tales especies son: A. capricorne, Coryphantha delicata L. Bremen, Echinocereus enneacanthus variedad brevispinus (W. O. Moore) L. D. Benson, , F. hamatacanthus y Mammillaria roseoalba Boed., por lo que es importante evitar el pastoreo y promover su conservación mediante algunos viveros o jardines, involucrando a los habitantes de los alrededores, los propietarios y las empresas que tienen acceso a las torres (Cuadro 1).

En el ANP las asociaciones de presencia de plantacactus más frecuentes son: E. stramineus, Thelocactus rinconensis (Poselg.) Britton et Rose y Mammillaria pottsii Scheer ex Salm-Dyck, con: A. lechuguilla. Además de E. stramineus con E. avenaceum, V. stenoloba, M. pottsii y $Z$. hispida, coincidiendo con lo citado para el municipio de García por Goettsch y Hernández (2006), quienes registran 65 géneros de leguminosas y 168 especies que coexisten en asociación con especies de las familias Cactaceae, Agavaceae, Poaceae y Asteraceae, entre otras, y con los registros de E. stramineus, C. leptocaulis y $N$. conoidea en asociación con Larrea tridentata Coult., P. glandulosa, Yucca filifera Hort. ex Engelm., Agave lechuguilla, Hechtia glomerata Zucc., y D. texanum (Estrada et al., 2004). Los resultados obtenidos difieren de los de Reyes y García (1999), quienes en un estudio realizado en Topolobampo, Sinaloa, observaron asociaciones de algunas especies de Opuntia con arbustos, y de Echinocereus y Mammillaria con rocas.

En Sierra Corral de los Bandidos, la especie con mayor valor de importancia por su frecuencia, cobertura y abundancia es $A$. lechuguilla, misma que a su vez proporciona, protección al suelo, humedad, nutrientes y sombra a las cactáceas asociadas, especialmente a las del género Echinocereus y C. leptocaulis, además del nicho que representa para la fauna presente. Moreno en 2001 destaca para el norte del estado, en el municipio de Anáhuac, a P. glandulosa, Castela texana Rose y $C$. leptocaulis como las especies de mayor importancia.

Agave lechuguilla fue la especie más frecuentemente asociada con las cactáceas en el ANP, por lo que desempeña un valioso papel como planta nodriza de éstas y seguramente como nicho importante de la fauna asociada con las cactáceas, mientras que Flores y Jurado (2003) citan para el desierto de Chihuahua a P. glandulosa y Jatropha dioica Sessé ex. Cerv., como las plantas nodrizas más frecuentes.

En la Sierra Corral de los Bandidos, al igual que lo indican Flores y Jurado (2003), J. dioica, P. glandulosa y $C$. leptocaulis se encuentran asociadas a Ferocactus hamatacanthus (Muehlenpf.) Britton et Rose y $O$. rastrera, además de Mimosa biuncifera Benth., Euphorbia antisiphylitica Zucc. y L. tridentata. En las asociaciones de poáceas y cactáceas se observó la preferencia de los géneros Opuntia y Corynopuntia al encontrarse con mayor frecuencia relacionados con las gramíneas, lo cual concuerda con Golubov et al. (2000).

La diferencia en cuanto a composición de especies entre las comunidades de cactáceas de las zonas del ANP de acuerdo con los índices cualitativos de Jaccard y Sorensen-Dice y Morisita $(M=0.44)$, sugiere el manejo específico de cada una de ellas para preservar su riqueza y diversidad, tal como lo indica Falk (1990) para otras áreas naturales protegidas. 
La diversidad florística del área natural protegida Sierra Corral de los Bandidos consiste de 112 especies vegetales, repartidas en 86 géneros pertenecientes a 37 familias. Las familias con mayor número de especies fueron Cactaceae, Poaceae, Mimosaceae, Asteraceae y Euphorbiaceae. Se encontraron 30 especies de cactáceas (27\% de la flora del ANP), agrupadas en 14 géneros.

El presente estudio aporta información sobre la diversidad florística del ANP Sierra Corral de los Bandidos, misma que supera en casi el $300 \%$ a lo citado en su programa de manejo. La información servirá a los administradores del área natural protegida para la toma de decisiones y establece las bases para el aprovechamiento de sus recursos forestales no maderables, especialmente para las cactáceas.

La zona de amortiguamiento presentó 87 especies vegetales, de las cuales 24 son cactáceas y representan el 22\%. Las especies de mayor densidad fueron: $A$. lechuguilla, T. muticus, V. stenoloba, y E. avenaceum. Mientras que la zona núcleo cuenta con 81 especies de las cuales 19 son cactáceas, y corresponden al 19\% de la flora muestreada. En ella, A. lechuguilla, V. stenoloba, T. muticus y $C$. pubens, fueron las taxa con mayor densidad. Existen 13 especies de cactáceas presentes en ambas zonas. No obstante, la mayor riqueza y diversidad florística se encontró en la zona núcleo.

En el ANP destaca la presencia de $A$. capricorne, $C$. delicada, E. enneacanthus var. brevispinus, E. poselgeri, $F$. hamatacanthus, M. plumosa, M. roseoalba y $M$. candida, que se encuentran dentro de algún estatus de la Norma Oficial Mexicana (NOM-059-ECOL-2001), por su distribución restringida y/o carácter endémico, 5 de ellas están en la zona de amortiguamiento y 5 en la zona núcleo.

Las asociaciones de cactáceas y plantas más frecuentes en Sierra Corral de los Bandidos fueron E. stramineus, $T$. rinconensis y $M$. pottsii con $A$. lechuguilla. Además de $E$. stramineus con $E$. avenaceum, con $V$. stenoloba, con $M$. pottsii y con Z. hispida.

Sierra Corral de los Bandidos es un importante representante del matorral desértico, por la riqueza de sus poblaciones de cactáceas, agaváceas y poáceas. Las cactáceas presentan especies de amplia distribución como las de los géneros Echinocereus, Cylindropuntia y Opuntia y algunas de distribución restringida como A. capricorne y $M$. plumosa, así como también diversos endemismos como las de los géneros Mammillaria, Astrophytum y Coryphantha entre otras.

La distribución de las cactáceas se relaciona con la presencia de especies asociadas que les sirven de especies nodriza al protegerlas de depredadores, brindarles sustrato y protección. Agave lechuguilla fue la especie más frecuentemente asociada con las cactáceas en el ANP, desempeñando un valioso papel como planta nodriza.

Existe notable diferencia en cuanto a composición de especies entre las comunidades de cactáceas de las zonas del ANP, toda vez que la similitud entre estas, correspondió al $23 \%$ y $38 \%$ de acuerdo con los índices cualitativos de Jaccard y Sörensen-Dice respectivamente, y afirmándose cuantitativamente con el índice Morisita $(\mathrm{M}=0.44)$. Por lo que se sugieren el manejo específico de cada una de ellas.

Se recomienda aprovechar la infraestructura existente por las torres de microondas para promover el desarrollo de viveros in situ para reproducción de especies y/o unidades de manejo de la flora silvestre autorizadas por el gobierno federal (UMAS) con fines de conservación, comercialización y repoblación en aquellas zonas donde el recurso esté disminuido. Asimismo, es prioritario hacer conciencia en vecinos, usuarios, autoridades y propietarios, sobre el control del pastoreo de ganado caprino y equino en estas zonas.

\section{Literatura citada}

Alanís, G., C. Velazco, R. Foroughbakhch, V. Valdéz y M. Alvarado. 2004. Diversidad florística de Nuevo León: especies en categoría de riesgo. Ciencia Universidad Autónoma de Nuevo León 7:209-218.

Alanís, F. G., G. Cano y M. Rovalo. 1996. Vegetación y flora de Nuevo León, una guía botánico ecológica. CEMEXImpresora Monterrey, Monterrey, Nuevo León. 251 p.

Alanís, F. G. y R. Ramírez. 2001. Caracterización del hábitat de distribución de Opuntia engelmannii (Salm-Dyck) Engelm. en el noreste de México y su importancia como forraje. In Memoria del tercer taller regional de cactáceas del noreste de México, G. Alanís, G. y A. Ledezma (eds.). Facultad de Ciencias Biológicas, Universidad Autónoma de Nuevo León, Monterrey. p. 31-36.

Braun-Blanquet, J. J. 1945. Plant sociology, the study of plant communities, traducción del alemán, revisión y edición de G.D. Fuller y H. S. Conrad, reimpreso por Eafner, New York. 439 p.

Bravo Hollis., H. 1978. Las cactáceas de México, vol. I. Universidad Nacional Autónoma de México, México, D.F. $743 \mathrm{p}$.

Bravo Hollis, H. y H. Sánchez Mejorada. 1991. Las cactáceas de México, vol. II y III. Instituto de Biología, Universidad Nacional Autónoma de México, México, D. F. 404 y 642 p.

Briones, O. 1984. Sinecología y florística de Lampazos de Naranjo, Nuevo León (México), con énfasis en la gran llanura. Tesis, Facultad de Biología, Universidad Autónoma de Nuevo León, Monterrey. 114 p.

Cabrera, J. y M. Gómez. 2005. Análisis florístico de la Cañada, Querétaro, México. Boletín de la Sociedad Botánica de México. 77:35-50.

Casas, G. 2005. Biodiversidad. Ciencia Ergo Sum. Universidad 
Autónoma del Estado de Toluca 12, (noviembre-febrero). www.redalyc.org/ consulta del 25 de junio del 2007.

Cavazos, C. 1977. Estudio de las comunidades vegetales de los márgenes del río Cabezones-Conchos en Nuevo León, México. Tesis, Facultad de Ciencias Biológicas, Universidad Autónoma de Nuevo León, San Nicolás de los Garza, Nuevo León. 50 p.

Dirección de Parques y Recursos Naturales del Gobierno del Estado de Nuevo León. 2002. Programa de manejo del Área Natural Protegida Sierra Corral de los Bandidos..Monterrey, Nuevo León. 75 p.

Estrada, E., C. Yen, A. Delgado y J. Villarreal. 2004. Leguminosas del centro del estado de Nuevo León, México. Anales del Instituto de Biología, Serie Botánica. Universidad Nacional Autónoma de México 75:73-85.

Falk, D. 1990. Integrated strategies for conserving plant genetic diversity. Annals of the Missouri Botanical Garden 77:38-47.

Flores, J. y E. Jurado. 2003. ¿Are nurse protégé interactions more common among plants from arid environments? Journal Vegetation Science 14:911-916.

García, E. 1973. Modificaciones al sistema de clasificación climática de Köppen, para adaptarlo a las condiciones de la República Mexicana. Instituto de Geografía, Universidad Nacional Autónoma de México, México, D.F. 243 p.

García, J. 1985. Estudio de las comunidades vegetales en el ejido Bustamante, Bustamante, Nuevo León, México. Tesis, Facultad de Biología, Universidad Autónoma de Nuevo León, Monterrey. 67 p.

Gobierno del Estado de Nuevo León. 2000. Decreto del Área Natural Protegida en la categoría de Zona Sujeta a la Conservación Ecológica denominada "Sierra Corral de los Bandidos", Periódico oficial, 24 de noviembre, Monterrey.

Gobierno del Estado de Nuevo León. 2002. Programa de manejo del área natural protegida "Sierra Corral de los Bandidos". Subsecretaría de Ecología, Dirección de Áreas Naturales y Parques del Estado, Monterrey. 94 p.

Goettsch, B. y H. Hernández. 2006. Beta diversity and similarity among cactus assemblages in the Chihuahuan desert. Journal of Arid Environments. 65:513-528.

Golubov, J., M. Mandujano y C. Montaña. 2000. Cactáceas asociadas a pastizales de Hilaria mutica (Bucal.) Benth. en la Reserva de la Biosfera de Mapimí, México. Cactáceas y Suculentas Mexicanas. 45: 84-89.

González, M. y A. Estrada. 2001. Cactáceas del norte del estado de Nuevo León, México. Memorias del XV Congreso mexicano de Botánica. Querétaro, Querétaro. México. 2001.

Gurevitch, J., M. Scheiner y A. Gordon 2002. The Ecology of Plants. Sinauer, Sunderland, Massachusetts. p. 319-349.

Guzmán, U., S. Arias y P. Dávila. 2003. Catálogo de cactáceas mexicanas. Universidad Nacional Autónoma de México y Comisión Nacional para el Uso y Conocimiento de la Biodiversidad. México, D.F. 315 p.

Hernández, H. y H. Godínez. 1994. Contribución al conocimiento de las cactáceas mexicanas amenazadas. Acta Botanica Mexicana 26:33-52.

Hernández, H. y R. Bárcenas. 1995. Endangered cacti in the
Chihuahuan desert: I. Distribution Patterns. Conservation Biology 9:1176-1188.

Hernández, H. y R. Bárcenas 1996.Endangered cacti in the Chihuahuan desert: II. Biogeography and Conservation. Conservation Biology 10:1200-1209.

Hershkovitz, M. y Zimmer, 1977. E. On the evolutionary origins of the cacti. Taxon 46:117-232.

Hunt, D. 1992. Convención sobre el Comercio Internacional de Especies Amenazadas (CITES)-Cactaceae checklist. Royal Botanic Gardens, Kew, Surrey. 190 p.

Instituto Nacional de Estadística, Geografía e Informática (INEGI). 1986. Síntesis geográfica del estado de Nuevo León. Primera reimpresión. Monterrey, Nuevo León. 160 p.

Matteucci, D. y A. Colma. 1982. Metodología para el estudio de la vegetación. Secretaría General de la Organización de los Estados Americanos, Programa Regional de Desarrollo Científico y Tecnológico. Washington, D. C. 163 p.

Moreno, T. A. 2001. Distribución espacial de Echinocereus enneacanthus Engelmann 1848 y Echinocereus papillosus Linke ex Rümpler 1885, y su asociación con la cobertura de diversas especies arbustivas y arbóreas en Anáhuac, Nuevo León. In Memoria del tercer taller regional de cactáceas del noreste de México, Alanís, G. y A. Ledezma (eds.). Facultad de Ciencias Biológicas. Universidad Autónoma de Nuevo León. Monterrey. p. 41-47.

Mueller-Dombois, D. y H. Ellenberg. 1974. Aims and methods of vegetation ecology. Wiley, New York. 547 p.

NOM-059-ECOL-2001. Norma Oficial Mexicana. Protección Ambiental-Especies nativas de México de flora y fauna silvestres-Categorías de riesgo y especificaciones para su inclusión, exclusión o cambio-lista de especies en riesgo. Diario Oficial de la Federación, 23 de abril de 2003. México, D. F.

Reyes, A. y E. García. 1999. Patrones espaciales de cactáceas en el desierto costero de Topolobampo. Sinaloa. I Congreso Latinoamericano y del Caribe de cactáceas y otras plantas suculentas. Sociedad Mexicana de Cactología, Oaxaca, Oaxaca $82 \mathrm{p}$.

Rocha, D. L. 2005. Análisis de la distribución de cactáceas en el estado de Nuevo León, México. Tesis doctorado Facultad de Biología, Universidad Autónoma de Nuevo León, Monterrey. $135 \mathrm{p}$.

Sauceda, J. 1985. Estudio florístico, ecológico y utilizable de las cactáceas del municipio de García, Nuevo León, México. Tesis, Facultad de Biología, Universidad Autónoma de Nuevo León, Monterrey. 67 p.

Schemske, W., B. Husband, M. Ruckelshaus, C. Goodwillie, I. Parker y J. Bishop. 1994. Evaluating approaches to the conservation of rare and endangered plants. Ecology 75:584-606.

Teixeira-Roth, V., V. Castro, A. Ceroni, A. y R. Eyzaguirre. 2004. Diversidad y densidad de la comunidad de cactáceas en el cerro Umarcata y quebrada Orobel en el valle del río Chillón (Lima) y su relación con los factores edáficos. Ecología Aplicada, Universidad Nacional Agraria La Molina, Lima 3:1726-2216.

The international plant names index (2004 versión). 2004.. http:// www.ipni.org/ consultado 26 de junio de 2007. 
Vargas, M. 1985. Fenología reproductiva, distribución de tallas y su influencia en la producción de frutos y semillas en una población de Echinocereus stramineus (Engelmann) Rümpler, en el ejido "Los Fierros", municipio de García, Nuevo León. Tesis, Facultad de Biología. Universidad Autónoma de Nuevo León. Monterrey. 78 p.
Villarreal Q., J. A. 2001. Listados florísticos de México. XXIII. Flora de Coahuila. Instituto de Biología, Universidad Nacional Autónoma de México, México, D.F. 138 p.

Waissman, N. B. S. 1982. The phytogeography of New México Cactaceae. Thesis of Master Degree. University of Texas at El Paso. 87 p.

Apéndice 1. Lista de especies asociadas a cactáceas en el área natural protegida Sierra Corral de los Bandidos en García, Nuevo León, México, obtenidas mediante los muestreos por cuadrantes y transectos adicionales, y número de individuos en Za: Zona de amortiguamiento y Zn: Zona núcleo.

\begin{tabular}{|c|c|c|c|c|}
\hline Familias & & Especies & $Z A$ & $Z N$ \\
\hline Acanthaceae & & Carlowrightia pubens A. Gray & 47 & 148 \\
\hline Adiantaceae & & Notholaena sinuata (Lag.) Klf. & 1 & 5 \\
\hline \multirow[t]{3}{*}{ Agavaceae } & (3) & Agave lechuguilla Torr. & 357 & 916 \\
\hline & & Agave striata Zucc. & 8 & 12 \\
\hline & & Yucca filifera Hort. ex Engelm. & 47 & 148 \\
\hline Amaryllidaceae & & Cooperia pedunculata Herb. & 0 & 4 \\
\hline Asclpidaceae & & Cynanchum barbigerum (Scheele) Shinners & 0 & 4 \\
\hline \multirow[t]{11}{*}{ Asteraceae } & (11) & Acourtia wrightii (A.Gray) Reveal et R.M. King & 7 & 1 \\
\hline & & Dyssodia micropoides (DC.) Loes. & 2 & 12 \\
\hline & & Dyssodia pentachaeta DC. BL Rob. & 68 & 54 \\
\hline & & Erigeron pulchellus Hook. & 35 & 11 \\
\hline & & Eupatorium coelestinum $\mathrm{L}$ & 0 & 2 \\
\hline & & Gymnosperma glutinosum Less & 6 & 32 \\
\hline & & Layia glandulosa Hook. et Arn. & 6 & 0 \\
\hline & & Parthenium incanum H.B.et K. & 5 & 2 \\
\hline & & Varilla texana A.Gray & 7 & 0 \\
\hline & & Viguiera stenoloba S.F.Blake & 105 & 191 \\
\hline & & Zexmenia hispida (Kunth) A. Gray & 57 & 65 \\
\hline Berberidaceae & & Berberis trifoliolata Moric & 2 & 1 \\
\hline \multirow[t]{3}{*}{ Boraginaceae } & (3) & Coldenia canescens D.C. & 16 & 7 \\
\hline & & Cordia boissieri A. DC. & 2 & 1 \\
\hline & & Heliotropium torreyi I.M. Johnst & 16 & 7 \\
\hline Brassicaceae & & Lesquerella lindheimeri (A.Gray) S.Watson & 0 & 6 \\
\hline Bromeliaceae & & Hechtia glomerata Zucc. & 2 & 1 \\
\hline Caesalpinaceae & & Caesalpinia mexicana A.Gray & 16 & 7 \\
\hline Capparaceae & & Koeberlinia spinosa Zucc. & 0 & 4 \\
\hline Commelinaceae & & Commelina erecta Hort. Berol. & 0 & 1 \\
\hline Convolvulaceae & & Evolvulus alsinoides Gardner & 16 & 80 \\
\hline Crassulaceae & & Sedum dendroideum Moc. et Sessé ex DC. & 2 & 0 \\
\hline Dracaenaceae & (2) & Dasylirion texanus Scheele & 3 & 2 \\
\hline & & Nolina texana S.Watson & 2 & 0 \\
\hline
\end{tabular}




\begin{tabular}{|c|c|c|c|c|}
\hline Familias & & Especies & $Z A$ & $Z N$ \\
\hline \multirow[t]{7}{*}{ Euphorbiaceae } & (7) & Bernardia myricaefolia Benth. et Hook.f. & 1 & 0 \\
\hline & & Croton texensis (Klotzsch) Müll.Arg. & 6 & 7 \\
\hline & & Euphorbia antisyphilitica J. Meyrán & 3 & 0 \\
\hline & & Euphorbia golondrina L.C.Wheeler & 14 & 46 \\
\hline & & Euphorbia revoluta Engelm. & 0 & 4 \\
\hline & & Jatropha dioica Sessé ex.Cerv. & 3 & 7 \\
\hline & & Phyllanthus polygonoides Spreng. & 5 & 3 \\
\hline Fabaceae & & Eysenhardtia polystachya Sarg. & 0 & 1 \\
\hline Fouquieriaceae & & Fouquieria splendens Engelm. & 2 & 0 \\
\hline \multirow[t]{2}{*}{ Lamiaceae } & (2) & Hedeoma drummondii Benth & 0 & 2 \\
\hline & & Salvia regla $\mathrm{Cav}$. & 2 & 0 \\
\hline \multirow[t]{3}{*}{ Malvaceae } & (3) & Hibiscus cardiophyllus Baill. & 1 & 0 \\
\hline & & Meximalva filipes (A. Gray) Fryxell & 8 & 12 \\
\hline & & Sphaeralcea endlichii Ulbr. & 1 & 1 \\
\hline \multirow[t]{6}{*}{ Mimosaceae } & (6) & Acacia berlandieri Benth. & 15 & 34 \\
\hline & & Acacia rigidula Benth. & 5 & 11 \\
\hline & & Calliandra eriophylla Benth. & 20 & 6 \\
\hline & & Mimosa biuncifera Benth. & 2 & 1 \\
\hline & & Pithecellobium ebano (Berland.) C.H.Müll. & 1 & 1 \\
\hline & & Prosopis glandulosa Torr. & 16 & 31 \\
\hline Nyctaginaceae & & Acleisanthes longiflora A. Gray & 2 & 3 \\
\hline Oleaceae & & Forestiera angustifolia Torr. & 0 & 2 \\
\hline Papaveraceae & & Eschscholtzia mexicana Greene & 1 & 0 \\
\hline \multirow[t]{14}{*}{ Poaceae } & (14) & Aristida adscencionis L. & 0 & 10 \\
\hline & & Aristida wrigtii Nash & 0 & 70 \\
\hline & & Bouteloua trifida Thurb. & 63 & 62 \\
\hline & & Cenchrus ciliaris $\mathrm{L}$. & 4 & 0 \\
\hline & & Chloris verticillata Nut & 8 & 0 \\
\hline & & Enneapogon desvauxii P. Beauv. & 6 & 0 \\
\hline & & Erioneuron avenaceum (H.B.et K.) Tateoka & 75 & 7 \\
\hline & & Erioneuron pulchellum (H.B.et K.) Tateoka & 18 & 0 \\
\hline & & Lycurus phleoides H.B.et K. & 43 & 0 \\
\hline & & Panicum hallii Basey & 26 & 5 \\
\hline & & Setaria macrostachya Kunth & 0 & 4 \\
\hline & & Stipa leucotricha Trin. et Rupr. & 2 & 5 \\
\hline & & Tridens muticus Nash & 137 & 137 \\
\hline & & Tridens sp. Roem. et Schult & 1 & 81 \\
\hline Polemoniaceae & & Gilia incisa Benth. & 4 & 0 \\
\hline Polygalaceae & & Polygala lindheimeri A. Gray & 9 & 0 \\
\hline Pteridaceae & & Adiantum capillus-veneris $\mathrm{L}$ & 0 & 1 \\
\hline
\end{tabular}




\begin{tabular}{|c|c|c|c|c|}
\hline Familias & & Especies & $Z A$ & $Z N$ \\
\hline \multirow[t]{2}{*}{ Rhamnaceae } & (2) & Condalia hookeri M.C. Johnst. & 2 & 0 \\
\hline & & Karwinskia humboldtiana (R. S.) Zucc. & 0 & 24 \\
\hline Rubiaceae & & Bouvardia ternifolia Schltdl. & 2 & 0 \\
\hline Scrophulariacea & & Leucophyllum frutescen I.M. Johnst. & 11 & 47 \\
\hline Selaginellaceae & & Selaginella wrightii Hiceron & 0 & 3 \\
\hline Solanaceae & & Lycium berlandieri Dunal & 0 & 6 \\
\hline \multirow[t]{2}{*}{ Verbenaceae } & (2) & Lantana horrida Hook & 2 & 0 \\
\hline & & Lantana macropoda Torr. & 3 & 7 \\
\hline \multirow[t]{3}{*}{ Zygophyllaceae } & (3) & Larrea tridentata Coult & 3 & 14 \\
\hline & & Porlieria angustifolia A.Gray & 18 & 3 \\
\hline & & Tribulus terrestris L. & 0 & 1 \\
\hline Totales 36 & & Totales 82 & 1344 & 2271 \\
\hline
\end{tabular}

Los taxa están citados con base en la nomenclatura de The International Plant Names Index (IPNI) http//:www.ipni.org

Apéndice 2. Listado florístico y parámetros estructurales de las especies en la zona de amortiguamiento del área natural protegida Sierra Corral de los Bandidos en García, Nuevo León, México (datos registrados mediante el muestreo por cuadrantes).

\begin{tabular}{|c|c|c|c|c|}
\hline Especies z-amortiguamiento & $\begin{array}{l}\text { Frecuencia } \\
\text { relativa }\end{array}$ & $\begin{array}{l}\text { Cobertura } \\
\text { relativa }\end{array}$ & Densidad relativa & $\begin{array}{l}\text { Valor de } \\
\text { importancia }\end{array}$ \\
\hline Acacia berlandieri & $2.59 \%$ & $3.20 \%$ & $0.72 \%$ & $2.17 \%$ \\
\hline Acleisanthes longiflora & $0.52 \%$ & $0.07 \%$ & $0.12 \%$ & $0.24 \%$ \\
\hline Acourtia wrightii & $0.52 \%$ & $0.01 \%$ & $0.36 \%$ & $0.30 \%$ \\
\hline Agave lechuguilla & $12.95 \%$ & $34.86 \%$ & $11.72 \%$ & $19.85 \%$ \\
\hline Agave striata & $1.04 \%$ & $1.26 \%$ & $0.24 \%$ & $0.85 \%$ \\
\hline Bouteloua trifida & $5.70 \%$ & $5.42 \%$ & $2.15 \%$ & $4.42 \%$ \\
\hline Bouvardia ternifolia & $0.52 \%$ & $0.07 \%$ & $0.12 \%$ & $0.24 \%$ \\
\hline Calliandra eriophylla & $1.04 \%$ & $0.60 \%$ & $0.48 \%$ & $0.70 \%$ \\
\hline Carlowrightia pubens & $5.18 \%$ & $2.63 \%$ & $1.79 \%$ & $3.20 \%$ \\
\hline Cenchrus ciliaris & $0.52 \%$ & $0.10 \%$ & $0.12 \%$ & $0.25 \%$ \\
\hline Chloris verticillata & $0.52 \%$ & $0.00 \%$ & $0.12 \%$ & $0.21 \%$ \\
\hline Coldenia canescens & $2.07 \%$ & $2.26 \%$ & $0.72 \%$ & $1.69 \%$ \\
\hline Coryphantha sulcata & $0.52 \%$ & $0.06 \%$ & $0.12 \%$ & $0.23 \%$ \\
\hline Cylindropuntia leptocaulis & $1.04 \%$ & $0.21 \%$ & $0.24 \%$ & $0.50 \%$ \\
\hline Dyssodia pentachaeta & $5.18 \%$ & $1.38 \%$ & $3.59 \%$ & $3.38 \%$ \\
\hline Echinocereus stramineus & $5.70 \%$ & $3.81 \%$ & $44.38 \%$ & $17.96 \%$ \\
\hline Enneapogon desvauxii & $0.52 \%$ & $0.09 \%$ & $0.24 \%$ & $0.28 \%$ \\
\hline Erigeron pulchellus & $3.11 \%$ & $2.32 \%$ & $1.32 \%$ & $2.25 \%$ \\
\hline Erioneuron avenaceum & $2.07 \%$ & $0.54 \%$ & $1.20 \%$ & $1.27 \%$ \\
\hline Erioneuron pulchellum & $2.59 \%$ & $1.08 \%$ & $1.08 \%$ & $1.58 \%$ \\
\hline
\end{tabular}




\begin{tabular}{|c|c|c|c|c|}
\hline Especies z-amortiguamiento & $\begin{array}{l}\text { Frecuencia } \\
\text { relativa }\end{array}$ & $\begin{array}{l}\text { Cobertura } \\
\text { relativa }\end{array}$ & Densidad relativa & $\begin{array}{l}\text { Valor de } \\
\text { importancia }\end{array}$ \\
\hline Euphorbia golondrina & $2.07 \%$ & $1.19 \%$ & $0.72 \%$ & $1.33 \%$ \\
\hline Evolvulus alsinoides & $0.52 \%$ & $2.50 \%$ & $0.36 \%$ & $1.13 \%$ \\
\hline Ferocactus hamatacanthus & $1.04 \%$ & $0.29 \%$ & $0.60 \%$ & $0.64 \%$ \\
\hline Gilia incisa & $1.04 \%$ & $0.11 \%$ & $0.24 \%$ & $0.46 \%$ \\
\hline Lantana horrida & $0.52 \%$ & $0.12 \%$ & $0.12 \%$ & $0.25 \%$ \\
\hline Layia glandulosa & $1.04 \%$ & $1.32 \%$ & $0.36 \%$ & $0.91 \%$ \\
\hline Lesquerella lindheimeri & $3.11 \%$ & $1.53 \%$ & $2.27 \%$ & $2.30 \%$ \\
\hline Leucophyllum frutescens & $1.04 \%$ & $0.26 \%$ & $0.60 \%$ & $0.63 \%$ \\
\hline Lycurus phleoides & $2.07 \%$ & $3.25 \%$ & $2.27 \%$ & $2.53 \%$ \\
\hline Mammillaria melanocentra & $1.55 \%$ & $1.08 \%$ & $0.84 \%$ & $1.16 \%$ \\
\hline Mammillaria pottsii & $2.07 \%$ & $0.16 \%$ & $2.27 \%$ & $1.50 \%$ \\
\hline Meximalva filipes & $0.52 \%$ & $0.90 \%$ & $0.12 \%$ & $0.51 \%$ \\
\hline Neolloydia conoidea & $2.07 \%$ & $0.32 \%$ & $3.23 \%$ & $1.87 \%$ \\
\hline Opuntia engelmannii & $0.52 \%$ & $0.02 \%$ & $0.12 \%$ & $0.22 \%$ \\
\hline Opuntia engelmannii spp. lindheimeri & $0.52 \%$ & $0.01 \%$ & $0.12 \%$ & $0.21 \%$ \\
\hline Panicum hallii & $1.04 \%$ & $0.93 \%$ & $1.32 \%$ & $1.10 \%$ \\
\hline Parthenium incanum & $1.55 \%$ & $1.48 \%$ & $0.36 \%$ & $1.13 \%$ \\
\hline Pithecellobium ebano & $0.52 \%$ & $1.13 \%$ & $0.12 \%$ & $0.59 \%$ \\
\hline Polygala lindheimeri & $1.55 \%$ & $0.23 \%$ & $0.48 \%$ & $0.76 \%$ \\
\hline Porlieria angustifolia & $1.55 \%$ & $0.76 \%$ & $0.48 \%$ & $0.93 \%$ \\
\hline Prosopis glandulosa & $1.55 \%$ & $3.37 \%$ & $0.60 \%$ & $1.84 \%$ \\
\hline Thelocactus rinconensis & $2.07 \%$ & $0.25 \%$ & $0.36 \%$ & $0.90 \%$ \\
\hline Tridens muticus & $6.74 \%$ & $4.54 \%$ & $6.94 \%$ & $6.07 \%$ \\
\hline Viguiera stenoloba & $8.29 \%$ & $10.88 \%$ & $3.59 \%$ & $7.59 \%$ \\
\hline Zexmenia hispida & $1.55 \%$ & $3.40 \%$ & $0.72 \%$ & $1.89 \%$ \\
\hline Totales 45 & $100 \%$ & $100 \%$ & $100 \%$ & $100 \%$ \\
\hline
\end{tabular}

Apéndice 3. Listado florístico y parámetros estructurales de las especies en la zona núcleo del área natural protegida Sierra Corral de los Bandidos en García, Nuevo León, México (datos registrados mediante el muestreo por cuadrantes).

\begin{tabular}{lllll}
\hline Especies zona núcleo & $\begin{array}{l}\text { Frecuencia } \\
\text { relativa }\end{array}$ & $\begin{array}{l}\text { Cobertura } \\
\text { relativa }\end{array}$ & $\begin{array}{l}\text { Densidad } \\
\text { relativa }\end{array}$ & $\begin{array}{l}\text { Valor de } \\
\text { importancia }\end{array}$ \\
\hline Acacia berlandieri & $2.31 \%$ & $0.81 \%$ & $2.21 \%$ & $1.78 \%$ \\
Acacia rigidula & $0.58 \%$ & $0.45 \%$ & $0.17 \%$ & $0.40 \%$ \\
Agave lechuguilla & $11.56 \%$ & $38.81 \%$ & $20.61 \%$ & $23.66 \%$ \\
Asistida adscecencionis & $0.58 \%$ & $0.10 \%$ & $0.68 \%$ & $0.45 \%$
\end{tabular}




\begin{tabular}{|c|c|c|c|c|}
\hline Especies zona núcleo & $\begin{array}{l}\text { Frecuencia } \\
\text { relativa }\end{array}$ & $\begin{array}{l}\text { Cobertura } \\
\text { relativa }\end{array}$ & $\begin{array}{l}\text { Densidad } \\
\text { relativa }\end{array}$ & $\begin{array}{l}\text { Valor de } \\
\text { importancia }\end{array}$ \\
\hline Asistida wrightii & $7.51 \%$ & $6.12 \%$ & $5.96 \%$ & $6.53 \%$ \\
\hline Bouteloua trifida & $2.89 \%$ & $7.08 \%$ & $1.36 \%$ & $3.78 \%$ \\
\hline Caesalpinia mexicana & $0.58 \%$ & $0.05 \%$ & $0.17 \%$ & $0.27 \%$ \\
\hline Carlowrightia pubens & $8.67 \%$ & $2.43 \%$ & $6.98 \%$ & $6.03 \%$ \\
\hline Coldenia canescens & $0.58 \%$ & $0.31 \%$ & $0.17 \%$ & $0.35 \%$ \\
\hline Cooperia pedunculata & $0.58 \%$ & $0.01 \%$ & $0.34 \%$ & $0.31 \%$ \\
\hline Coryphantha sulcata & $0.58 \%$ & $0.08 \%$ & $0.17 \%$ & $0.28 \%$ \\
\hline Croton texensis & $2.89 \%$ & $0.68 \%$ & $1.02 \%$ & $1.53 \%$ \\
\hline Cylindropuntia leptocaulis & $4.05 \%$ & $3.84 \%$ & $3.41 \%$ & $3.77 \%$ \\
\hline Cynanchum barbigerum & $1.16 \%$ & $0.46 \%$ & $0.34 \%$ & $0.65 \%$ \\
\hline Dasylirion texanus & $0.58 \%$ & $1.65 \%$ & $0.17 \%$ & $0.80 \%$ \\
\hline Dyssodia micropoides & $2.31 \%$ & $0.46 \%$ & $1.02 \%$ & $1.27 \%$ \\
\hline Dyssodia pentachaeta & $0.58 \%$ & $0.52 \%$ & $2.39 \%$ & $1.16 \%$ \\
\hline Echinocereus stramineus & $2.31 \%$ & $1.12 \%$ & $19.08 \%$ & $7.50 \%$ \\
\hline Erigeron pulchellus & $0.58 \%$ & $0.09 \%$ & $0.17 \%$ & $0.28 \%$ \\
\hline Eupatorium coelestinum & $0.58 \%$ & $1.53 \%$ & $0.17 \%$ & $0.76 \%$ \\
\hline Euphorbia golondrina & $4.62 \%$ & $0.37 \%$ & $2.21 \%$ & $2.40 \%$ \\
\hline Euphorbia revoluta & $0.58 \%$ & $0.03 \%$ & $0.34 \%$ & $0.32 \%$ \\
\hline Evolvulus alsinoides & $3.47 \%$ & $0.67 \%$ & $1.53 \%$ & $1.89 \%$ \\
\hline Ferocactus hamatacanthus & $0.58 \%$ & $0.03 \%$ & $0.17 \%$ & $0.26 \%$ \\
\hline Forestiera angustifolia & $0.58 \%$ & $2.55 \%$ & $0.17 \%$ & $1.10 \%$ \\
\hline Gilia incisa & $0.58 \%$ & $0.05 \%$ & $0.17 \%$ & $0.27 \%$ \\
\hline Gymnosperma glutinosum & $1.16 \%$ & $0.48 \%$ & $0.85 \%$ & $0.83 \%$ \\
\hline Hechtia glomerata & $0.58 \%$ & $0.69 \%$ & $0.17 \%$ & $0.48 \%$ \\
\hline Hedeoma drummondii & $0.58 \%$ & $0.02 \%$ & $0.17 \%$ & $0.26 \%$ \\
\hline Heliotropium torreyi & $0.58 \%$ & $0.38 \%$ & $0.17 \%$ & $0.38 \%$ \\
\hline Karwinskia humboldtiana & $2.31 \%$ & $3.17 \%$ & $0.85 \%$ & $2.11 \%$ \\
\hline Larrea tridentata & $0.58 \%$ & $0.71 \%$ & $0.34 \%$ & $0.54 \%$ \\
\hline Lesquerella lindheimeri & $1.16 \%$ & $0.59 \%$ & $0.68 \%$ & $0.81 \%$ \\
\hline Leucophyllum frutescens & $3.47 \%$ & $1.21 \%$ & $1.87 \%$ & $2.18 \%$ \\
\hline Lophophora williamsii & $4.05 \%$ & $0.07 \%$ & $1.36 \%$ & $1.83 \%$ \\
\hline \multirow[t]{2}{*}{ Lycium berlandieri } & $1.16 \%$ & $3.02 \%$ & $0.51 \%$ & $1.56 \%$ \\
\hline & $0.58 \%$ & $0.15 \%$ & $0.17 \%$ & $0.30 \%$ \\
\hline Mammillaria heyderi & $0.58 \%$ & $0.01 \%$ & $0.17 \%$ & $0.25 \%$ \\
\hline Mammillaria plumosa & $0.58 \%$ & $0.13 \%$ & $8.69 \%$ & $3.13 \%$ \\
\hline Mammillaria roseoalba & $1.73 \%$ & $0.13 \%$ & $0.51 \%$ & $0.79 \%$ \\
\hline Opuntia engelmannii spp lindheimeri & $1.16 \%$ & $0.01 \%$ & $0.34 \%$ & $0.50 \%$ \\
\hline Panicum halli & $0.58 \%$ & $0.57 \%$ & $0.34 \%$ & $0.50 \%$ \\
\hline Prosopis glandulosa & $1.73 \%$ & $1.74 \%$ & $1.53 \%$ & $1.67 \%$ \\
\hline
\end{tabular}




\begin{tabular}{lllll} 
Especies zona núcleo & $\begin{array}{l}\text { Frecuencia } \\
\text { relativa }\end{array}$ & $\begin{array}{l}\text { Cobertura } \\
\text { relativa }\end{array}$ & $\begin{array}{l}\text { Densidad } \\
\text { relativa }\end{array}$ & $\begin{array}{l}\text { Valor de } \\
\text { importancia }\end{array}$ \\
\hline $\begin{array}{l}\text { Setaria macrostachya } \\
\text { Sphaeralcea endlichii }\end{array}$ & $0.58 \%$ & $0.35 \%$ & $0.34 \%$ & $0.42 \%$ \\
& $0.58 \%$ & $0.15 \%$ & $0.17 \%$ & $0.30 \%$ \\
Stipa leucotricha & $1.16 \%$ & $1.02 \%$ & $0.34 \%$ & $0.84 \%$ \\
$\begin{array}{l}\text { Tridens muticus } \\
\text { Viguiera stenoloba }\end{array}$ & $4.05 \%$ & $2.49 \%$ & $4.26 \%$ & $3.60 \%$ \\
Zexmenia hispida & $7.51 \%$ & $11.45 \%$ & $4.43 \%$ & $7.80 \%$ \\
& $2.31 \%$ & $1.36 \%$ & $0.68 \%$ & $1.45 \%$ \\
Totales & & & & \\
& $\mathbf{1 0 0} \%$ & $\mathbf{1 0 0} \%$ & $\mathbf{1 0 0} \%$ & $\mathbf{1 0 0} \%$ \\
\hline
\end{tabular}

